\title{
POLÍTICAS PÚBLICAS E MONITORAMENTO NA EDUCAÇÃO INFANTIL
}

FABIANA SILVA FERNANDES

\section{RESUMO}

Este artigo trata de concepções de políticas públicas e de monitoramento como instrumento para acompanhar a implementação e a execução de uma política, de um programa público ou de uma ação governamental. 0 propósito é subsidiar a elaboração de um sistema de monitoramento para a educação infantil a partir de reflexões sobre essa etapa da educação básica como política pública para o oferecimento de educação de qualidade para crianças de 0 a 5 anos. 


\section{RESUMEN}

Este artículo trata de concepciones de políticas públicas y de monitoreo como instrumento para acompañarla implementación y la ejecución de una política, de un programa público o de una acción gubernamental. El propósito es subsidiar la elaboración de un sistema de monitoreo para la educación infantil a partir de reflexiones sobre esta etapa de la educación básica como política pública para el ofrecimiento de educación de calidad para niños de 0 a 5 años de edad.

palabras clave políticas pÚBlicas - MONITOREO • EDUCACIÓN INFANTIL・CALIDAD DE LA EDUCACIÓN.

\section{ABSTRACT}

This article deals with conceptions of public policies and monitoring as instruments to oversee the implementation and execution of policy, of a public program or of a governmental action. The purpose is to support the development of a monitoring system for early childhood education, based on beliefs about this stage of basic education, as public policy for offering quality education to children from 0 to 5 years.

KEYWORDS PUBLIC POLICIES - MONITORING - EARLY CHILDHOOD EDUCATION • EDUCATIONAL QUALITY. 
1 A proposta de desenvolver um sistema de monitoramento da educação infantil no município do Rio de Janeiro é da Fundação Carlos

Chagas, coordenado por Eliana Bhering, e conta com financiamento do Banco Interamericano de Desenvolvimento. Nesse projeto, estão envolvidas equipes de pesquisadores da Fundação Carlos Chagas e da Universidade Federal do Rio de Janeiro.

\section{INTRODUÇÃO}

Este artigo tem por finalidade refletir sobre políticas públicas e monitoramento para subsidiar uma concepção de um sistema de monitoramento de política de educação infantil. A pesquisa que serviu de base para este artigo integra um projeto de intervenção na área da educação infantil no município do Rio de Janeiro ${ }^{1}$ com vistas a conceber um sistema de monitoramento para acompanhar as ações municipais na área da educação infantil e garantir a implementação de um projeto educacional de qualidade para essa etapa da educação básica.

O monitoramento é um importante mecanismo de acompanhamento das políticas públicas, tendo o propósito de permitir a obtenção de informações que subsidiem o desenvolvimento de uma política, um programa ou projeto.

No caso da educação infantil, o monitoramento pode compreender a definição de indicadores que permitam a mensuração da oferta e a avaliação das condições de atendimento, incluindo o perfil das crianças atendidas e a qualidade do trabalho pedagógico efetuado pelas instituições de educação infantil. 
Sendo a educação infantil municipal uma política pública, é importante compreender o significado de política pública, para, em seguida, compreender em que momento desse processo se situa o monitoramento.

Nesse sentido, este texto foi organizado de forma a apresentar diferentes abordagens sobre o conceito e a estrutura de política pública, o conceito de monitoramento e seu lugar no processo de política pública e o monitoramento como ferramenta de gestão das políticas e processos pedagógicos para a educação infantil municipal.

\section{POLÍTICAS PÚBLICAS: PRINCÍPIOS E DINÂMICA}

Política pública é um conjunto de decisões em torno de uma realidade social, com o propósito de mantê-la ou modificá-la mediante a definição de objetivos, formas de ação e alocação de recursos necessários.

Saravia (2006) afirma que uma política pública é desenvolvida pelo setor público, mas também envolve a participação da comunidade, definindo-se seu objetivo de forma democrática.

De acordo com Torres,

Las políticas públicas expresan de manera concreta las formas institucionalizadas que rigen la interacción gubernativa entre la sociedad y el Estado. Ponen en evidencia la naturaleza y la composición interna del sistema jerárquico de autoridad y dan cuenta del régimen de competencias y responsabilidades en el ejercicio del gobierno. (2004, p. 19)

Como atividade do Estado, a política pública fortaleceu-se progressivamente, na década de 1980 , com a deterioração da capacidade de resposta do modelo de planejamento econômico estatal às necessidades da população frente à crise econômica e com os anseios pela participação democrática nas decisões estatais (SARAVIA, 2006).

Proporcionando uma nova concepção de atividade governamental, em que a ação fundamentada no planejamento deslocava-se para a ideia de política pública, possibilitou-se a compreensão das funções do Estado sob outra perspectiva: a 
análise do funcionamento do Estado, em torno de suas leis e de sua estrutura, foi complementada pela análise dos fluxos e da dinâmica de seu funcionamento, incluindo a participação dos atores no processo de se fazer política e as relações entre eles e as agências públicas. "A análise estrutural, anatômica, do Estado e da administração continua válida, mas, aos poucos, vai-se incorporando uma visão da dinâmica, da fisiologia, do funcionamento estatal" (SARAVIA, 2006, p. 26).

Da perspectiva de Parada (2006), convergente com a de Saravia (2006), não basta compreender o ordenamento das atividades do setor público como algo que define sua organização, pois essa é uma concepção restrita sobre o papel do governo. Convém compreendê-lo como instrumento de realização das políticas públicas, o que aponta para a importância dos resultados produzidos pelo governo, em detrimento de uma análise que se limite a observar sua estrutura (PARADA, 2006).

$\mathrm{O}$ autor discorre, ainda, sobre a diferença entre política e política pública, apresentando a primeira como um conceito mais amplo, relativo ao poder, e a segunda como forma de manejar os assuntos públicos, ainda que ambas se influenciem reciprocamente.

\section{Las políticas públicas son un factor común de la política y de las decisiones del gobierno y de la oposición. Así, la política puede ser analizada como la búsqueda de establecer políticas públicas sobre determinados temas, o de influir en ellas. A su vez, parte fundamental del que hacer del gobierno se refiere al diseño, gestión y evaluación de las políticas públicas. (PARADA, 2006, p. 67)}

Verifica-se que a política, se considerada do ponto de vista mais amplo, compreende tanto as propostas de políticas públicas quanto aquelas que, efetivamente, se concretizam.

Nesse sentido, as políticas públicas permitem estudar diversos aspectos da política, tais como "la discussión de la agenda pública por toda la sociedad, las elecciones entre candidatos y sus programas, las actividades del gobierno, las actividades de la oposición, los esfuerzos analíticos sobre estos temas" (PARADA, 2006, p. 68). 


\section{ETAPAS OU MOMENTOS DO PROCESSO DE POLÍTICA}

\section{PÚBLICA}

O processo de política pública, do ponto de vista analítico, apresenta diversas etapas, com a participação de distintos atores, coalizações e procedimentos. Nessa seção do texto, serão apresentadas quatro concepções sobre os diferentes momentos da política pública, buscando apontar semelhanças e algumas distinções entre a abordagem de diferentes autores.

Saravia (2006) identifica sete etapas ou momentos do processo de política pública: momento da agenda, momento da elaboração, formulação, implementação, execução, acompanhamento e avaliação.

O momento da agenda refere-se à definição dos fatos sociais que deverão ser incorporados na lista de prioridades do poder público. Para sua inclusão na agenda, o fato social adquirirá a qualidade de um problema social, o que justificaria uma intervenção pública legítima, e será alvo de debates na sociedade.

O momento da elaboração refere-se à identificação e delimitação de um problema, sobre o qual serão determinadas alternativas possíveis de ação, bem como a avaliação dos custos e efeitos de cada uma delas e indicação das prioridades (SARAVIA, 2006).

No momento de formulação, são definidos os objetivos e os marcos jurídico, administrativo e financeiro da alternativa eleita a mais conveniente.

Distinguindo elaboração de formulação, Saravia discorre sobre o caráter preparatório da primeira, que teria por finalidade subsidiar a decisão política, a qual estaria circunscrita ao segundo momento, ou seja, a formulação é a "decisão tomada por um político ou pelo Congresso, e sua formalização por meio da norma jurídica” (2006, p. 32).

$\mathrm{O}$ autor estabelece, também, uma distinção entre as próximas etapas do processo de política pública, ou seja, a implementação e a execução. Conceitua a implementação como a preparação para o momento de execução, isto é, como o momento do planejamento e da organização do aparato administrativo para a execução de uma política, envolvendo, para isso, recursos humanos, financeiros, materiais e 
tecnológicos. "Trata-se da preparação para pôr em prática a política pública, a elaboração de todos os planos, programas e projetos que permitirão executá-la" (SARAVIA, 2006, p. 34). Já a execução é definida como o conjunto de ações determinadas no momento anterior, ou seja, é a política posta em prática, a sua realização efetiva.

Em seguida, há o momento de acompanhamento, referente à supervisão da execução de uma atividade, de modo a oferecer informação para assegurar o cumprimento dos objetivos e o estabelecimento de operações para a correção de eventuais problemas no curso do processo.

Por fim, há a avaliação, que, quando feita a posteriori, pode fornecer informações sobre os efeitos produzidos na sociedade pelas políticas públicas.

Por outro lado, Parada (2006) distingue quatro etapas analíticas: origem, desenho, gestão e avaliação das políticas públicas. A origem corresponde à agenda, o desenho consiste no planejamento, a gestão é a etapa da execução, e a avaliação coincide com o descrito por Saravia (2006).

Ambos os autores, Saravia e Parada, explicitam as etapas do processo de política pública com algumas aproximações em relação ao esquema clássico do Ciclo de Políticas, ainda que apresentem algumas diferenças conceituais e analíticas.

O esquema clássico constitui-se em etapas sucessivas, com valor explicativo sobre o processo de formulação de política pública, tendo por propósito ilustrar diferentes componentes envolvidos, evidenciando as atividades de planejamento, gestão e avaliação dos programas. Tal como divulgado por Januzzi et al. (2009), o esquema clássico do Ciclo de Políticas (Policy Cycle) apresenta as seguintes etapas:

1. Definição da Agenda Política (Agenda-Setting), que implica o reconhecimento de uma questão social como problema público e passível de ação governamental.

2. Formulação de Políticas e Programas (Policy Formulation), compreendendo os processos $\mathrm{e}$ atividades para a construção de soluções.

3. Tomada de Decisão Técnica-Política (Decision Making) sobre as alternativas formuladas. 
4. Implementação de Políticas e Programas (Policy Implementation), relacionada com a gestão do programa, a locação dos recursos e o cumprimento das ações previstas.

5. Avaliação das Políticas e Programas, que é a análise dos esforços empreendidos de modo a verificar se existem necessidades de mudanças ou a descontinuação, no caso de o problema não mais compor a agenda.

A Agenda Política é o conjunto de assuntos e problemas considerados como relevantes, em determinado momento, por gestores públicos e comunidade política, concepção que converge com a definição de agenda explicitada por Saravia (2006). As questões que entram nessa agenda são problemas sociais que se transformaram em questões públicas, alvo da intervenção política e administrativa do Estado.

A construção dessa agenda submete-se a diferentes compreensões do papel do Estado; da organização do aparato estatal, das instituições públicas e das relações existentes entre os atores políticos; da burocracia; e de demais setores organizados da sociedade, pois é composta de problemas e demandas definidas por diferentes atores sociais e políticos.

$\mathrm{Na}$ etapa da formulação da política, dentro dessa perspectiva clássica, os problemas expressos na agenda política são transformados em leis, programas e propostas de ações. Para a elaboração dos programas e propostas de ação, os procedimentos existentes e disponíveis para os gestores públicos são as metodologias de planejamento e as técnicas de elaboração de projetos, aliadas ao conhecimento setorial específico. Nessa etapa de formulação são previstas a análise da viabilidade política das estratégias de ação, programas e projetos, a análise do custo-benefício das soluções propostas e a previsão dos recursos e procedimentos necessários para a implementação das propostas.

Na fase de implementação dos programas, projetos e ações, a política pública ${ }^{2}$ passa a ser executada, de modo a mudar o problema social abordado, mediante a gestão de recursos e ações. Portanto, essa etapa compreende o conjunto de ações realizadas, envolvendo a
2 Cabe destacar que Januzzi et al. (2009) estabelece uma diferenciação entre política pública e programa público afirmando que a natureza das políticas públicas pode ser de ordem distributiva, redistributiva ou regulatória, universal e focalizada, e pode assumir diferentes formatos: diretrizes estratégicas de governo, leis, decretos normativos, criação de organizações ou programas que conferem aos documentos normativos a operacionalidade. Já o programa público é menos amplo, sendo um instrumento operacional das políticas. "Mais especificamente, trata-se de um conjunto sistêmico de ações programadas e articuladas entre si, com o objetivo de atender uma demanda pública específica, encampada na agenda de prioridades de políticas públicas do Estado ou governo. Assim, um programa social é um conjunto de atividades direcionadas para solucionar um problema vivenciado pela sociedade, no seu todo ou por grupos" (ROSSI et al. apud JANUZZI et al., 2009, p. 108). 
[...] programação das atividades, previsionamento de recursos financeiros, alocação de recursos humanos, mobilização de agentes, interlocução com atores estratégicos, manejo dos mecanismos que assegurem a governabilidade das atividades e correção de cursos, caso se identifiquem obstáculos ou surpresas não antecipadas. (JANUZZI et al., 2009, p. 112)

Finalmente, na etapa da avaliação somativa, os resultados obtidos são confrontados com os resultados esperados, de modo a subsidiar as decisões em torno da necessidade de corrigir ações e definir novos planos de ação, de reformular o programa, ou mesmo de descontinuá-lo.

[...] esse modelo de representação tem a grande virtude de facilitar o entendimento do processo complexo de interação de diversos agentes, nos múltiplos estágios por que passa a formulação de políticas públicas oferecendo um marco metodológico geral para análises isoladas de cada etapa do processo ou das relações de cada uma com as demais, à frente ou à jusante. (JANUZZI et al., 2009, p. 113)

Torres (2004) apresenta uma concepção distinta, expondo o que ele denomina estruturação das políticas públicas, decompondo-a em: (1) formação de políticas; e (2) traçado das políticas. $\mathrm{O}$ primeiro refere-se à etapa de formulação da política, composta pelas intencionalidades do governo, a definição da agenda e o enunciado da política. O segundo, estabelecendo-se algumas aproximações com Saravia e Parada, refere-se aos momentos da implementação e da execução das políticas, contemplando o enunciado da política, a definição da agenda operativa e seus desdobramentos territoriais.

Fazendo-se uma comparação entre os autores abordados, para auxiliar na compreensão das diferentes abordagens, tem-se o seguinte esquema: 
ESQUEMA 1 - Quadro comparativo entre os diferentes autores que abordam a política pública

\begin{tabular}{|c|c|c|c|}
\hline \multicolumn{2}{|c|}{ PROCESSO DE POLÍTICA PÚBLICA } & CICLO DE POLÍTICA PÚBLICA & ESTRUTURAÇÃO DE POLÍTICA PÚBLICA \\
\hline \multicolumn{2}{|l|}{ Etapas/momentos } & Etapas & $\begin{array}{l}\text { Momentos de produção/reprodução de } \\
\text { políticas públicas }\end{array}$ \\
\hline SARAVIA (2006) & PARADA (2006) & JANUZZI ET AL. (2009) & TORRES (2004) \\
\hline $\begin{array}{l}\text { Agenda } \\
\text { Elaboração } \\
\text { Formulação }\end{array}$ & \multirow{2}{*}{$\begin{array}{l}\text { Origem } \\
\text { Desenho }\end{array}$} & Agenda & Formulação da política \\
\hline $\begin{array}{l}\text { Implementação } \\
\text { (planejamento) }\end{array}$ & & $\begin{array}{l}\text { Formulação } \\
\text { Tomada de decisão } \\
\text { (Planejamento) }\end{array}$ & \multirow{3}{*}{ Traçado da política } \\
\hline $\begin{array}{l}\text { Execução (gestão) } \\
\text { Acompanhamento }\end{array}$ & Gestão & Implementação (gestão) & \\
\hline Avaliação & Avaliação & Avaliação & \\
\hline
\end{tabular}

\section{CONSIDERAÇÕES SOBRE A ESQUEMATIZAÇÃO DO PROCESSO DE POLÍTICA PÚBLICA}

A esquematização do processo de política pública compõe um quadro lógico das políticas para efeito de esclarecimento e de análise, pois, na realidade, o processo pode acontecer de forma improvisada e fora da ordem sugerida, ainda que essas etapas estejam geralmente presentes (SARAVIA, 2006).

Do ponto de vista da prática política e social, as diferentes etapas não ocorrem necessariamente de forma causal e consecutiva, isso porque:

[...] la discusión social, la propuesta de políticas públicas y

el proceso político tienen dinámicas distintas, si bien entre ellos existen efectos recíprocos, aunque asimétricos.

En algún momento de la dinámica de los temas públicos

es posible la aceptación de una política, su rediseño

o extinción. Este momento requiere que coincidan la preocupación social, la existencia de una solución técnica y el apoyo político. (PARADA, 2006, p. 72)

Torres (2004) afirma que o conceito de estruturação das políticas públicas permite uma capacidade explicativa maior do processo de produção e de seus desdobramentos, ainda que considere também não ser linear, uma vez que está submetido a um processo de seleção, hierarquização e apropriação permanente das formas, relações e significados. 
Saravia (2006) sugere alguns fatores que influenciam as políticas públicas, principalmente em relação à definição dos temas e das prioridades a ser alvo de ações de governo. Em primeiro lugar, menciona "as contingências que afetam a dinâmica estatal”, as quais se relacionam, fundamentalmente, com a capacidade técnica dos planejadores e demais funcionários públicos envolvidos e também com poder político de diferentes grupos sociais organizados, cuja capacidade de articulação dentro do sistema político tem uma importância muito grande. Menciona também as instituições estatais, uma vez que desempenham um papel categórico nas políticas públicas:

[...] delas emanam ou elas condicionam as principais decisões. Sua estrutura, seus quadros e sua cultura organizacional são elementos que configuram a política. As instituições impregnam as ações com seu estilo específico de atuação. (SARAVIA, 2006, p. 37)

De acordo com o autor:

Os estudos de política pública mostram a importância das instituições estatais tanto como organizações, pelas quais os agentes públicos (eleitos ou administrativos) perseguem finalidades que não são exclusivamente respostas a necessidades sociais, como também configurações e ações que estruturam, modelam e influenciam os processos econômicos com tanto peso, como as classes e os grupos de interesse. (2006, p. 37)

Para Torres (2004), a estruturação das políticas públicas é produto de intenso processo político, mediante o qual surgem e tomam forma projetos e diferentes interesses de agentes (indivíduos), instituições e discursos.

Sobre os aspectos intervenientes no processo de política pública, Parada (2006) pronuncia-se considerando limitações reais do ciclo de política pública na realidade. Nesse sentido, apresenta cada etapa analítica do processo, buscando discutir aspectos que interferem, principalmente, na definição da origem, ou seja, da agenda.

Uma vez que nem toda ideia entra na agenda e que nem todos os temas da agenda convertem-se em programas, o autor 
discute alguns aspectos que interferem na formulação, implementação e execução das políticas públicas, inclusive impossibilitando o percurso de todas as etapas de forma homogênea $\mathrm{e}$ sistemática, tal como definido no modelo analítico.

O primeiro aspecto, acerca do debate público, apresenta algumas dificuldades que surgem na transição das ideias para a ação pública. Considerando a realidade das democracias latino-americanas, Parada discorre sobre características comuns a elas que são a prática do lobby, a corrupção e a falta de transparência no financiamento, o que geraria desigualdades entre os diferentes grupos que reivindicam espaços nas agendas governamentais. Esse fato é importante, pois fere as regras do jogo democrático, em que os interesses dos diferentes grupos e setores sociais deveriam competir e confluir para a formulação das políticas públicas.

Condiciona, também, a definição da agenda à diferença de representatividade entre os grupos sociais, em que alguns possuem uma capacidade maior de representação de seus interesses em detrimento de outros.

Nos meandros da escolha do problema que comporá a agenda, é possível verificar a relação entre a política e as políticas públicas, na medida em que um fato que se torne um problema social é objeto de ação pública, quando existe viabilidade política:

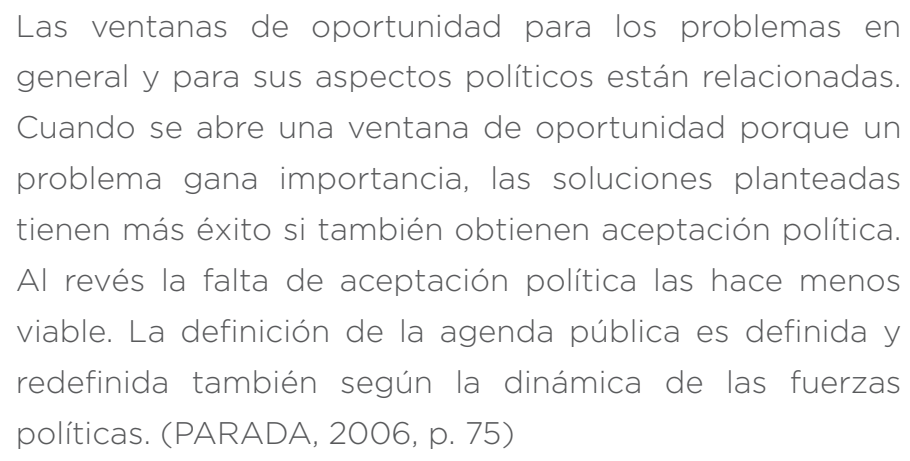

Como consequência, nota-se que a estabilidade da agenda depende da governabilidade do sistema e do nível de estruturação do sistema político, em que estão incluídos os sistemas partidários e suas estratégias para alcançar o poder: financiamento de campanhas qualificadas pelo abuso 
do poder econômico, coalizações de partidos com diferentes interesses e perspectivas de governo, formulação de programas de governo difíceis de concretizarem políticas públicas, entre outros.

Como mecanismo para contornar esses problemas, o autor aposta na participação de amplos setores sociais na definição da agenda, bem como na formulação, execução e avaliação das políticas públicas:

Ella permite una distribución más equitativa del poder y una mayor visibilidad de los problemas sociales [...]

La participación es un modo privilegiado en que los ciudadanos y las organizaciones que los agrupan puedan valer sus opiniones en el período que va entre un acto eleccionario y otro.

Ella representa un complemento indispensable de la burocratización de los actos gubernativos, otorga mayor transparencia al sistema político y agiliza la consideración de los problemas sociales más relevantes [...]

La participación es también un modo privilegiado de expresar la participación social; de hacer presente a los diferentes grupos, tanto en sus demandas específicas, como en su visión del mundo. Es una manera en la que la sociedad se reconoce a sí misma. (PARADA, 2006, p. 80)

Por fim, em relação à formulação das políticas públicas e sua implementação e execução, cabe destacar a fluidez das fronteiras entre as atividades próprias de um governo e aquelas correspondentes às campanhas políticas (PARADA, 2006), porque, nas campanhas, há estratégias de persuasão que desconsideram as questões técnicas e políticas envolvidas nos programas desenvolvidos por um governo, acentuando a inviabilidade ou a falta de efetividade de políticas públicas propostas nos planos de governo.

Conhecer o conceito de política pública, seu processo e os obstáculos e desafios a serem enfrentados na sua concretização são importantes, uma vez que, tal como afirmado por Torres (2004), permitem uma aproximação com os princípios e a dinâmica que regem a relação entre a esfera política e a ação política. 


\section{O MONITORAMENTO COMO MECANISMO DE GESTÃO DAS POLÍTICAS SOCIAIS}

Considerando o processo de política pública tal como abordado por Saravia (2006), Parada (2006) e Torres (2004) e o esquema clássico do Ciclo de Políticas, apesar das distintas perspectivas teóricas abordadas por esses autores, verifica-se que o monitoramento, como ferramenta para subsidiar a gestão das políticas sociais, situa-se numa etapa de acompanhamento de políticas em fase de execução.

De acordo com Carvalho, o monitoramento, que tem por finalidade garantir a efetividade de uma ação pública, "registra e armazena informações substantivas no continuum da ação de uma política/programa, ou seja, recai sobre a cadeia de ações e relações processadas" (2011, p. 1). Essas informações visam à avaliação e à produção de recomendações para a melhoria ou a correção de ações no decorrer da execução de uma política ou um programa público.

Januzzi et al. (2009), ao situarem o monitoramento no ciclo de políticas, fazem uma diferenciação entre monitoramento e avaliação como mecanismos de acompanhamento e a avaliação como etapa do ciclo. Para o autor, a avaliação, como etapa do ciclo, é realizada após à execução. Não se confunde com as atividades de monitoramento e avaliação, realizadas por meio dos sistemas de monitoramento, e as pesquisas de avaliação, realizadas em qualquer momento do ciclo. Por esse motivo, ele propõe denominar essa etapa de avaliação somativa.

É importante considerar também que o sistema de monitoramento, quando dispõe de informações analíticas, ${ }^{3}$ permite que um gestor consiga interpretar uma situação inadequada ou indesejável no curso do programa implementado. Quando os indicadores de monitoramento não permitem uma explicação satisfatória, então é momento de refletir sobre a necessidade de se encomendar uma pesquisa de avaliação.

Monitoramento e Avaliação de Programas são ambos termos cunhados para designar procedimentos técnicos formais de acompanhamento de programas, focados na análise da eficiência, eficácia e efetividade dos mesmos [...]. Monitoramento e avaliação são processos analíticos
3 Januzzi $(2005,2011)$ propõe que o Sistema de Monitoramento amplie suas possibilidades de uso, voltando-se não somente para o gerenciamento de metas e prazos de ações, mas também para a análise comparativa e sistêmica de indicadores, dentro de uma série temporal. Nesse sentido, discorre sobre a definição de indicadores de natureza explicativa que permitam analisar uma política ou programa público, fornecendo subsídios o "exercício sistemático de análise de indicadores representativos dos fluxos de desembolsos financeiros, de realização de atividades-meio, de entrega de produtos e de inferência de resultados dos programas junto a seus públicos-alvo, segundo critérios clássicos de avaliação de Políticas - como equidade, eficácia, eficiência e efetividade" (2011, p. 43). 
Considerando as especificidades de cada um desses processos, Jannuzzi (2004) diferencia os indicadores de monitoramento, que são aqueles que sintetizam as informações sobre o ritmo e a forma de implementação de um programa ou de uma política pública, dos indicadores de avaliação, que abordam os resultados e os efeitos desse mesmo processo.

Por meio dos indicadores, o processo de monitoramento deve reunir informações detalhadas, possibilitando uma leitura mais aprofundada do processo de implantação e execução das ações e, por consequência, contribuindo para que a efetividade da ação pública seja alcançada.

Os indicadores são as ferramentas analíticas que permitem o monitoramento de dada política ou programa social, pois permitem “'filmar' o processo de implementação dos programas formulados" (ANTICO; JANUZZI, s.d., p. 3).

Os indicadores sociais são, portanto, medidas, em geral quantitativas, e dotadas de um significado social substantivo. A finalidade do indicador é "substituir, quantificar ou operacionalizar um conceito social abstrato, de interesse teórico (para pesquisa acadêmica) ou programático (para formulação de políticas)" (JANUZZI, 2004, p. 15). Além disso, informa sobre determinado aspecto da realidade social, constituindo-se em recurso metodológico, empiricamente referido.

Os programas de monitoramento, concebidos como processos analíticos que subsidiam o gestor público com informações sobre a execução de determinados programas, requerem a estruturação de sistemas de indicadores. 


\section{CICLO DE POLÍTICAS E INDICADORES SOCIAIS COMO MECANISMOS DE MONITORAMENTO}

Dentro do ciclo de políticas e programas, há diferentes tipos de indicadores que subsidiam o monitoramento dos distintos momentos do programa, bem como das pesquisas de avaliação.

Cada etapa do ciclo de políticas apoia-se em indicadores. Na definição da agenda política, os indicadores produzidos pelas instituições oficiais de estatísticas, por exemplo, são importantes para dimensionar os problemas sociais.

Na elaboração do diagnóstico, os indicadores permitem a definição do público-alvo, de modo que as intervenções sejam pensadas, levando em consideração suas características e necessidades.

\section{Para desenvolver programas no campo da educação \\ básica, por exemplo, é preciso conhecer não apenas as condições de acesso à escola, a infraestrutura escolar, o desempenho dos alunos, mas também aspectos relacionados às condições de vida dos estudantes, como moradia, nível de pobreza e rendimento familiar, acesso a serviços de saúde, escolaridade dos pais, fatores esses que certamente podem afetar ou potencializar as ações programáticas específicas. (JANUZZI et al., 2009, p. 116)}

Nessa fase, referente à elaboração do diagnóstico, são importantes os indicadores construídos a partir dos censos demográficos.

No caso do acompanhamento da implementação ${ }^{4}$ de programas, são necessários indicadores que revelem informações regulares sobre as ações, constituindo-se, portanto, em ferramentas imprescindíveis para a gestão desses programas, quando estiverem em plena operação.

Para acompanhar a implementação dos programas e, posteriormente, para gestão, quando eles entrarem em plena operação, são necessários indicadores que permitam acompanhar regularmente as ações programadas, do previsionamento e alocação do gasto à produção dos serviços e, idealmente, aos eventuais resultados e impactos esperados quando da idealização dos programas. São
4 Como a discussão sobre o monitoramento e seus indicadores, nesta parte do texto, fundamentase, principalmente, em Januzzi, o conceito de implementação adotado não se diferencia do conceito de execução, uma vez que os indicadores de monitoramento, apropriados para o momento da implementação de um programa, referem-se à etapa de execução, na perspectiva de Januzzi. 
Os indicadores referentes à natureza do ente indicado talvez sejam os mais importantes para uma equipe gestora, pois subsidiam o gerenciamento do processo de implementação das políticas públicas, permitindo organizar os indicadores conforme sua utilidade nas diferentes etapas de um ciclo de gestão. São indicadores referentes a três componentes importantes na operacionalização de uma política ou programa, quais sejam: recurso (indicador-insumo ou indicador de esforço); realidade empírica (indicador-produto ou indicador de resultado); e processo (indicador-processo) (BRASIL, 2010; JANUZZI, 2011).

Constituindo-se em insumos básicos para todas as etapas do processo de formulação e implementação das políticas públicas, os indicadores sociais devem ser definidos de acordo com cada fase desse processo, fornecendo informações pertinentes e subsídios para a tomada de decisões.

Assim, tomando o processo de formulação e implementação em seus moldes clássicos, na fase do Diagnóstico, os indicadores do tipo produto viabilizam a caracterização empírica do contexto sócio espacial em questão, a gravidade dos problemas sociais, a dimensão quantitativa das carências e demandas de serviços públicos a atender. Na fase da especificação de programas, os indicadores do tipo insumo traduzem em termos quantitativos a dotação de recursos exigidos pelas diferentes opções de programas sugeridos. Na implementação de programas selecionados, os indicadores de processo permitem monitorar a alocação operacional de recursos humanos, físicos e financeiros planejados. Na avalição dos programas implementados, indicadores de diferentes tipos são usados para medir a eficiência, eficácia e efetividade social das soluções sugeridas. (JANUZZI, 2004, p. 32)

\section{SISTEMA DE INDICADORES DE MONITORAMENTO}

O conjunto de indicadores que descreve ou permite analisar uma determinada realidade social ou mesmo um programa 
ou política é o Sistema de Indicadores. Alguns exemplos de sistemas de indicadores são os referidos aos setores como saúde, educação e economia, como: Sistema de Indicadores de Saúde, Sistema de Indicadores de Educação e Sistema de Indicadores para Mercado de Trabalho.

A estruturação de sistemas de indicadores de monitoramento, como um aspecto relacionado ao aprimoramento da gestão de programa, tem reflexos do contexto de reforma da administração pública, fundamentalmente da preocupação com a transparência e a responsabilidade pública. Nesse sentido, Januzzi et al. (2009) se propõem a discutir a importância dos sistemas de indicadores para o monitoramento das atividades e a produção de serviços dos programas, tendo em vista o referencial conceitual apresentado sobre o ciclo de políticas e programas.

O sistema de indicadores não deve, necessariamente, apresentar muitas informações, mas deve conter informações de diferentes fontes e ser organizado de modo sintético para os gestores.

Um sistema de indicadores de monitoramento não é um sistema de gestão operacional do programa, que provê acesso aos incontáveis registros diários e individuais de operação de convênios, prestação de serviços, recursos transferidos, projetos e atividades concluídas. Um sistema de monitoramento vale-se do(s) sistema(s) de gestão dos programas para buscar informações, integrá-las segundo unidades de referência comum (município, escola etc.), sintetizá-las em indicadores e conferir-Ihes significado analítico. (JANUZZI et al., 2009, p. 118)

Um bom sistema de monitoramento deve contar com indicadores que permitem a análise comparativa das informações ao longo do tempo e para as distintas unidades de prestação de serviço, pois ao analisar-se o comportamento dos indicadores num intervalo de tempo é possível identificar falhas operativas do programa.

Dispostos em painéis ou em sistemas informatizados, os indicadores devem ser atualizados com a regularidade necessária ou adequada para a tomada de decisão, e os sistemas 
devem ser alimentados com dados dos cadastros e registros administrados pelos gestores, atualizados constantemente.

Diferentemente do que se passa nas pesquisas de ava-
liação, na estruturação de sistemas de monitoramento
não se prevê levantamentos primários de dados. Pode ser
necessário criar rotinas de coleta de dados que operem
forma dos círculos normais de produção de serviços dos
programas, mas é preciso fazer esforços para aproveitar
as informações geradas no âmbito de operação cotidiana
dos programas. (JANUZZl et al., 2009, p. 117)

Telles (2002) problematiza a construção de indicadores sociais explicitando as relações entre os aspectos técnicos, normativos e políticos que permeiam a realidade social e os indicadores sociais existentes. Permite situar a produção dos indicadores sociais numa perspectiva menos técnica, enfatizando o sentido normativo e político das medidas, uma vez que a realidade social é uma construção que se dá nas relações sociais em um contexto histórico, da mesma forma que os indicadores sociais. Essa reflexão, em uma abordagem sociológica, sobre a elaboração dos instrumentos de medida social, conjugada com a construção da realidade social, permite à autora afirmar a impossibilidade de se reduzir os indicadores à dimensão técnica e metodológica, uma vez que envolvem a definição de premissas relacionadas ao modo de se compreender, historicamente, os fatos sociais. Nesse sentido, a produção de indicadores está estritamente vinculada à construção dos fatos sociais, possuindo dimensões cognitiva e descritiva, relacionadas com o aspecto técnico e metodológico dos indicadores, e parâmetros normativos, relacionados às prioridades e fatos sociais elegidos das políticas públicas.

Além disso, Telles (2003) defende que os problemas sociais devem ser debatidos com base nas desigualdades existentes nas cidades e seus territórios, e não na "construção dos 'mínimos sociais' como parâmetros para a discussão sobre os padrões de inclusão/exclusão social” (p. 1), o que também reforça o sentido normativo e político dos indicadores sociais.

A produção dos indicadores sociais, ganha, portanto, um sentido político e também normativo, explícita e abertamente 
colocados no suposto de que a apropriação pelos cidadãos

das informações relativas às suas condições de vida e sobre as discrepâncias sociais estampadas na cidade é um componente importante na luta pela democratização da política e pela justiça social. (TELLES, 2003, p. 1)

As relações entre conhecimento, ética e política, assim como a reflexão sobre as desigualdades sociais presentes nas cidades e seus territórios, tornam-se uma necessidade veemente, de modo a garantir a obtenção de medidas e referências de análise de determinada realidade social vinculada a uma concepção de inclusão que transcende a definição de "mínimos sociais". Isso significa que, "por trás da grade de índices e medidas fornecida pelas estatísticas há o lento, tortuoso e quase sempre conflituoso processo de construção social dos 'objetos' ou dos 'atos sociais' que são alvo do debate e da ação política” (TELLES, 2003, p. 3).

Consequentemente, os indicadores podem ser compreendidos como elementos que participam da construção da realidade social, e não somente instrumentos de medição, o que exigiria uma compreensão ampliada da realidade social e do conjunto de indicadores e demais informações disponíveis, considerando os desafios atuais.

[...] vemos hoje em operação o que poderíamos chamar a 'política dos pequenos números' que sugere outros vetores ou princípios de totalização - totalização estatística, totalização política. Não mais as verticalidades que remetiam às regulações centralizadas das relações sociais e das conexões políticas, ancoradas nas formas espaciais de suas configurações e distribuições. Seria um exercício interessante reconstruir o jogo de causalidades e circunstâncias que levam a esses deslocamentos de referências: as novas realidades urbanas que escapam por todos os lados de categorias e medidas tradicionais, mas também o jogo dos atores que ganha formatos plurais e descentrados e as novas configurações da ação pública e das políticas sociais - mudanças de fundo nas formas de regulação sociais e regulação política. (TELLES, 2003, p. 10) 
Ainda que o olhar sobre o espaço venha adquirindo importância, existe o risco de fragmentação da realidade social, uma vez que os dados e indicadores podem estar desconectados de processos estruturadores e de

[...] mediações, redes e conexões que permitiram sua tradução política. Mas então isso significa reconhecer que a produção dos indicadores está hoje no centro da tensão entre gestão e política, entre a lógica gestionária que vem tomando conta do cenário atual, e a política enquanto construção (e disputa por) de novas formas de regulação social (e distribuição da riqueza social). (TELLES, 2003, p. 10)

Nota-se que a autora permite refletir sobre a produção de indicadores na educação infantil tendo como ponto de partida a ampliação de possibilidades e capacidades dos sistemas municipais de educação, levando-se em consideração não as necessidades mínimas para acesso e atendimento, mas sim a valorização da educação infantil como um direito da criança. Ademais, os indicadores para a educação infantil devem ser desenhados com o propósito de identificar e permitir a compreensão de aspectos relacionados às formas de organização e gestão das escolas e instâncias administrativas responsáveis e o acompanhamento do trabalho pedagógico realizado nas unidades.

\section{SISTEMA DE MONITORAMENTO DE POLÍTICAS E PROGRAMAS DE EDUCAÇÃO INFANTIL}

A oferta de educação infantil no Brasil é um dever do Estado, tal como estabelecido pela Constituição Federal de 1988. Definida como primeira etapa da educação básica, pela Lei de Diretrizes e Bases da Educação (Lei n. 9394/1996), a educação infantil compreende creches, para as crianças de 0 a 3 anos, e pré-escolas, para as crianças de 4 e 5 anos.

Antes de 2006, a pré-escola também era oferecida para as crianças de 6 anos, mas, com a Emenda Constitucional n. 53/2006, esse grupo da população passou a ser atendido na etapa subsequente, o que resultou na ampliação do número de anos do ensino fundamental. 
Em 2009, foi aprovada a Emenda Constitucional n. 59/2009, modificando a redação dos incisos I e VII do art. 208, de forma a prever a obrigatoriedade do ensino de 4 a 17 anos. Como resultado dessa medida, a frequência à pré-escola tornou-se obrigatória.

Salienta-se o fato de que a educação infantil deve ser oferecida prioritariamente pelos municípios, tal como previsto no artigo 11 da Lei de Diretrizes e Bases da Educação (Lei n. 9394/1996). Também, segundo o referido artigo, é incumbência dos municípios a organização, manutenção e desenvolvimento de órgãos e instituições oficiais dos seus respectivos sistemas de ensino, integrados às políticas e planos educacionais da União e dos estados. Esse inciso reflete um "projeto político mais amplo que investia de autoridade as estruturas político-administrativas locais antes concentradas nas instâncias centrais" (GENTILINI, 2010, p. 61), tendo como implicação a autonomia e a responsabilização dos municípios pela formulação de sua própria política educacional, em consonância com as normas e diretrizes nacionais para a educação.

Portanto, após a Constituição de 1988, reconheceu-se a autonomia dos entes federativos, e os municípios assumiram novas responsabilidades na oferta de políticas públicas e na gestão de áreas sociais, o que gerou alguns desafios para os governos locais, como a necessidade de garantir a governabilidade do sistema municipal e a capacidade de negociação com os demais entes federativos. Também se tornou necessário investir na capacidade administrativa e técnica de servidores municipais e ocupantes de cargos políticos para interpretar leis, formular planos, definir políticas públicas, elaborar projetos políticos educacionais (GENTILINI, 2010) e, não menos importante, implementar, executar e acompanhar as ações desenvolvidas.

Além das responsabilidades municipais pela educação básica, o papel de coordenação do governo federal vem estabelecendo, desde a reorganização da educação brasileira, na década de 1990, mecanismos de financiamento e controle das políticas educacionais dos diferentes entes federativos, entre eles a elaboração de diretrizes de formação de professores, 
parâmetros curriculares e os sistemas de avaliação em larga escala.

No caso da educação infantil, nos últimos dois anos, o Ministério da Educação (MEC), juntamente com o Instituto Nacional de Estudos e Pesquisas Educacionais Anísio Teixeira (Inep), tem buscado inseri-la numa Política Nacional de Avaliação da Educação Básica, compreendendo também o ensino fundamental e médio. Desde então, a avaliação da educação infantil tem sido objeto de reflexões e debates entre setores da administração pública, organizações da sociedade civil, fundações e universidades.

Nesse contexto, ficou clara a posição de educadores e instituições compromissados com a área da educação infantil, que buscaram situar a avaliação numa perspectiva distinta das avaliações de desempenho realizadas no ensino fundamental e no ensino médio. Além de reafirmarem a concepção de avaliação presente nos documentos oficiais - que orientam a utilização da avaliação envolvendo diferentes aspectos da ação educativa, como a observação e o acompanhamento das crianças e da proposta pedagógica da instituição - discorrem sobre sua importância para avaliar a organização do espaço educativo, de modo a promover a oferta de condições adequadas para o pleno desenvolvimento das crianças.

Esse cuidado com os limites da avaliação permitiu a diferenciação dela "na educação infantil" e "da educação infantil", sintetizada pelo educador Vital Didonet (2012) e adotada amplamente na área: a avaliação na educação infantil refere-se ao processo educativo propriamente dito, enfocando o fazer pedagógico por meio de atividades de observação e acompanhamento das crianças, e a avaliação da educação infantil situa-se no contexto da política nacional de educação, uma vez que está relacionada com as finalidades da educação infantil no âmbito social.

As preposições "na" e "da" constantes do título distinguem dois objetos e dois contextos da avaliação. A avaliação na educação infantil se refere àquela feita internamente no processo educativo, focada nas crianças enquanto sujeitos e coautoras de seu desenvolvimento. Seu âmbito é o 
microambiente, o acontecer pedagógico e o efeito que gera sobre as crianças. A avaliação da educação infantil toma esse fenômeno sociocultural ("a educação nos primeiros cinco anos de vida em estabelecimentos próprios, com intencionalidade educacional, formalizada num projeto político-pedagógico ou numa proposta pedagógica"), visando responder se e quanto ele atende à sua finalidade, a seus objetivos e às diretrizes que definem sua identidade. Essa questão implica perguntar-se sobre quem o realiza, o espaço em que ele se realiza e suas relações com o meio sociocultural. Enquanto a primeira avaliação aceita uma dada educação e procura saber sobre seus efeitos sobre as crianças, a segunda interroga a oferta que é feita às crianças, confrontando-a com parâmetros e indicadores de qualidade. (DIDONET, 2012, p. 1, grifos do autor)

Apesar da clareza sobre o papel da avaliação na educação infantil, seu desenho tem sido um desafio, ainda mais considerando a heterogeneidade das instituições que atendem as crianças na faixa etária do 0 aos 5 anos quanto à qualidade (infraestrutura, organização das instituições, trabalho pedagógico e cuidados) e recursos materiais, humanos e financeiros disponíveis, tal como demonstrado por Campos et al. (2010).

Sendo as políticas para a educação infantil, sua implementação e acompanhamento aspectos relacionados à qualidade, ${ }^{5}$ nota-se a importância da avaliação na verificação das condições de oferta da educação infantil, mas também do monitoramento para acompanhar a execução dos programas e ações destinados a essa etapa da educação básica e garantir que as condições de atendimento sejam adequadas.

Por esse motivo, há a proposta de concepção de um sistema de monitoramento da educação infantil no Rio de Janeiro para subsidiar o acompanhamento da política municipal, com o propósito de oferecer um serviço educacional de qualidade, com boa cobertura, recursos suficientes e adequados, boa infraestrutura, profissionais com formação e com projetos e práticas pedagógicas coerentes com as orientações curriculares do município para as creches e pré-escolas.
5 No documento "Parâmetros Nacionais de Qualidade para a Educação Infantil”, da Secretaria de Educação Básica do Ministério da Educação (BRASIL, 2006) foram estabelecidos os aspectos apontados como importantes para a melhoria da qualidade da educação infantil brasileira: as políticas para a educação infantil, sua implementação e acompanhamento; as propostas pedagógicas das instituições de educação infantil; a relação estabelecida com as famílias das crianças; a formação regular e continuada dos professores e demais profissionais; a infraestrutura necessária ao funcionamento dessas instituições. 
Uma vez que a educação infantil é considerada, neste trabalho, um processo dinâmico e fruto de negociações entre diferentes atores, compreende-se que o monitoramento deve englobar as instâncias responsáveis pelas distintas etapas do processo de políticas públicas, ou seja, os responsáveis pela formulação e implementação da educação infantil, os órgãos de gestão do sistema e as unidades de ensino, em que são concretizadas as políticas de educação infantil, por meio das práticas pedagógicas.

Nesse sentido, são observados, no município do Rio de Janeiro, três níveis de informação, relacionados às instâncias comprometidas com a educação infantil no município: o primeiro nível é o sistema educacional, sob a responsabilidade da Secretaria Municipal de Educação (SME), que responde pelas condições de oferta educacional no município, em relação à cobertura, infraestrutura, recursos materiais, financeiros e humanos e orientações curriculares; o segundo nível, intermediário, são as Coordenadorias Regionais de Educação, órgãos descentralizados de gerenciamento, responsáveis pela supervisão das instituições e pelo fornecimento de suporte técnico e pedagógico; e o terceiro nível, as unidades educacionais, que executam o projeto pedagógico da instituição, mediante a organização do trabalho pelo estabelecimento de rotinas de atividades de educação e cuidado, em que estão presentes recursos pedagógicos e suplementos necessários para a prática de higiene e alimentação, planejamento do professor e distribuição do tempo e do espaço de trabalho com as turmas de crianças.

Considerando esses níveis do sistema e as responsabilidades de cada um no processo de política pública, a proposta de monitoramento tem sido elaborada, primeiramente, pela identificação dos eixos analíticos e a definição das unidades de análise (JANNUZZI, 2011) no nível central da administração e na unidade educacional. Sabendo que à SME cabe a formulação e a implementação da política, de programas e das ações voltadas à rede municipal de ensino, no que se refere à educação infantil, as dimensões ou os aspectos identificados para compor o sistema de monitoramento são as condições de oferta educacional, cujos indicadores incidirão 
sobre a cobertura da educação infantil e o perfil das crianças atendidas, a infraestrutura existente e os recursos humanos e materiais utilizados. No nível das unidades, os indicadores referem-se à caracterização da gestão escolar e das práticas pedagógicas, estando em discussão os componentes que poderão ser monitorados, como os recursos materiais para a realização do trabalho pedagógico, a infraestrutura das salas e os tipos de atividades realizadas, tendo como base as orientações curriculares da $\mathrm{SME}^{6}$ e as estratégias para o envolvimento dos pais.

Nota-se, portanto, que, a partir da discussão teórica sobre políticas públicas e monitoramento, foi exercida uma breve reflexão sobre a educação infantil, sua estrutura e dinâmica de funcionamento, e identificados a finalidade do monitoramento na educação infantil, as instâncias que deverão ser monitoradas e os aspectos que deverão orientar a busca pelas fontes de informação e a formulação dos indicadores para o acompanhamento da execução de ações na educação infantil.

\section{ALGUMAS CONSIDERAÇÕES}

As reflexões sobre políticas públicas visam a fornecer um quadro teórico para que o processo de elaboração, implementação e execução de políticas para a educação infantil seja compreendido, assim como o momento de monitorar as ações para subsidiar a tomada de decisões sobre os rumos da educação infantil e sobre a gestão das ações que compõem a política.

Nesse sentido, o monitoramento, como mecanismo de acompanhamento, tem por propósito auxiliar a administração pública e as instituições educativas na supervisão das atividades executadas nas instâncias administrativas, nas unidades de educação e entre elas pela análise do fluxo das ações. Isso permitirá a organização de informações sobre a consecução dos objetivos dessa etapa da educação básica para que eventuais problemas, carências e demandas sejam detectados em tempo.

Permitindo a construção de um quadro de determinada política ou programa, o monitoramento fornece uma
6 Cabe destacar que os aspectos a serem monitorados, em relação ao nível das instituições de educação infantil, foram definidos também a partir de trabalho de avaliação, feito em 2012 e 2013, coordenado por Eliana Bhering. A análise dos resultados dessa avaliação, realizada numa amostra representativa de instituições, permitiu observar a qualidade dos ambientes de creches e pré-escolas, identificando as necessidades e fragilidades das instituições, em relação ao trabalho pedagógico. Os instrumentos utilizados para esse trabalho foram as escalas americanas Escala de Avaliação de Ambientes para Bebês e Crianças Pequenas - Creche (ITERS) e Escala de Avaliação de Ambientes de Educação Infantil (ECERS). 
imagem dos processos, fluxos e resultados, assumindo uma perspectiva descritiva ou formativa. Numa perspectiva descritiva, permite acompanhar a execução de uma política, subsidiando o seu gerenciamento, mas também, numa perspectiva formativa, favorece as tomadas de decisão a partir de reflexões sobre o desenvolvimento das ações, de modo a aprimorar o objeto monitorado (BHERING et al., 2013).

Tendo como finalidade garantir uma política de educação infantil de qualidade, que ofereça às crianças atendidas condições adequadas para o seu desenvolvimento, espera-se que o sistema de monitoramento esteja comprometido com ambas as perspectivas, fornecendo subsídios para a gestão das ações e dos recursos necessários para a oferta da educação infantil de qualidade, assim como para o aperfeiçoamento do trabalho pedagógico.

\section{REFERÊNCIAS}

ANTICO, Cláudia; JANNUZZI, Paulo de M. Indicadores e a gestão de políticas públicas. S.1.: Fundação do Desenvolvimento Administrativo, s/d. Disponível em: <http://www.fundap.sp.gov.br/debatesfundap/pdf/ Gestao_de_Poi\%C3\%ADticas_Publicas/Indicadores_e_Gest\%C3\%A3o_de_ Pol\%C3\%ADticas_P\%C3\%BAblicas.pdf>. Acesso em: 15 jan. 2014.

BHERING, Eliana et al. Ambientes de unidades municipais de educação infantil do município do Rio de Janeiro: uma proposta de formação e avaliação. São Paulo: Fundação Carlos Chagas, Banco Interamericano de Desenvolvimento, 2013.

BRASIL. Constituição (1988). Emenda Constitucional n. 53, de 19 de dezembro de 2006. Dá nova redação aos arts. 7, 23, 30, 206, 208, 211 e 212 da Constituição Federal e ao art. 60 do Ato das Disposições Constitucionais Transitórias. Diário Oficial da União, Brasília, DF, 20/12/2006, p. 5.

. Constituição (1988). Emenda Constitucional n. 59, de 11 de novembro de 2009. Acrescenta $\S 3^{\circ}$ ao art. 76 do Ato das Disposições Constitucionais Transitórias para reduzir, anualmente, a partir do exercício de 2009, o percentual da Desvinculação das Receitas da União incidente sobre os recursos destinados à manutenção e desenvolvimento do ensino de que trata o art. 212 da Constituição Federal, dá nova redação aos incisos I e VII do art. 208, de forma a prever a obrigatoriedade do ensino de quatro a dezessete anos e ampliar a abrangência dos programas suplementares para todas as etapas da educação básica, e dá nova redação ao $\S 4^{\circ}$ do art. 211 e ao $\S 3^{\circ}$ do art. 212 e ao caput do art. 214, com a inserção neste dispositivo de inciso VI. Diário Oficial da União, Brasília, DF, 12/11/2009, p. 8. 
Lei de Diretrizes e Bases da Educação Nacional (n. 9394). Brasil, 1996.

BRASIL. Ministério da Educação. Secretaria de Educação Básica. Parâmetros Nacionais de Qualidade para a Educação Infantil. Brasília: MEC/SEB, 2006.

BRASIL. Ministério do Planejamento, Orçamento e Gestão. Secretaria de Planejamento e Investimentos Estratégicos. Indicadores de Programas - Guia Metodológico. Brasília: Ministério do Planejamento, Orçamento e Gestão, 2010. Disponível em: <www.planejamento.gov.br/secretarias/upload/ arquivos/spi/publicações/100324_indicadores-guia_metodologico.pdf>. Acesso em: 6 ago. 2013.

CAMPOS, Maria M. M. et al. Educação infantil no Brasil: avaliação qualitativa e quantitativa. Relatório Final. São Paulo: Fundação Carlos Chagas, Banco Interamericano de Desenvolvimento, Ministério da Educação, 2010. Disponível em: <www.fcc.org.br/pesquisa/eixostematicos/educacaoinfantil/ pdf/relatorio_final.pdf>. Acesso em: 16 maio 2014.

CARVALHO, Maria do Carmo B. de. 0 papel do monitoramento no processo de avaliação. Avaliação de processo, resultados em impactos. Curso de Extensão Universitária sobre Metodologias de Avaliação de Políticas Públicas e construção de indicadores sociais. São Paulo: PUC, 2011. p. 1-14.

DIDONET, Vital. A avaliação na e da educação infantil. Brasília, jun. 2012.

GENTILINI, João Augusto. Planejamento da educação, projeto político e autonomia: desafios para o poder local. São Paulo: Cultura Acadêmica, 2010.

JANUZZI, Paulo de M. Conceitos básicos. In: JANUZZI, Paulo de M. Indicadores sociais no Brasil. Conceitos, fontes de Dados e Aplicações. Campinas: Alínea, 2004. p. 13-36.

Indicadores para diagnóstico, monitoramento e avaliação de programas sociais no Brasil. Revista do Serviço Público, Brasília, v. 56, n. 2, p. 137-160, abr./jun. 2005.

Monitoramento analítico como ferramenta para aprimoramento da gestão de programas sociais. Revista da Rede Brasileira de Monitoramento e Avaliação, n. 1, p. 38-67, jan.jjun. 2011.

JANUZZI, Paulo de M. et al. Estruturação de sistemas de monitoramento e especificação de pesquisas de avaliação, os problemas de programas públicos no Brasil são. In: FRANZESE, C. et al. Reflexões para Ibero-América: avaliação de programas sociais. Brasília: Enap, 2009. p. 101-138.

PARADA, Eugenio Lahera. Política y políticas públicas. In: SARAVIA, Henrique; FERRAREZI, Elisabete. Políticas Públicas. Brasília: Enap, 2006, v. I. p. 67-95.

SARAVIA, Enrique. Introdução à Teoria da Política Pública. In: SARAVIA, Henrique; FERRAREZI, Elisabete. Políticas Públicas. Brasília: Enap, 2006, v. I. p. 21-42.

TELLES, Vera da Silva. Medindo coisas, produzindo fatos, construindo realidades sociais. In: SEMINÁRIO INTERNACIONAL SOBRE INDICADORES SOCIAIS PARA INCLUSÃO SOCIAL. São Paulo: Núcleo de Estudos e Pesquisas em Seguridade e Assistência Social do Programa de Estudos Pós-graduados da Pontifícia Universidade Católica de São Paulo, 15-16 de maio de 2003. 
TORRES, Pedro Medellín. La política de las políticas públicas: propuesta teórica y metodológica para el estudio de las políticas en países de frágil institucionalidad. Santiago de Chile: CEPAL, 2004. Disponível em: <http:/www.cepal.org/ publicaciones/xml/5/15555/sps93_lc1270.pdf>. Acesso em: 15 jan. 2014.

FABIANA SILVA FERNANDES

Pesquisadora da Fundação Carlos Chagas

fsfernandes@fcc.org.br 
